\title{
The stress analysis of low rise to span three-pinned circular arch-ribbed domes
}

F. A. AULD

Dr P. Broughton, Lloyd's Register of Shipping

I have been involved in the analysis and testing of skeletal frameworks of a general structural form, in which account was taken of non-linearities attributable to gross deformation.

31. It is unlikely that a structure with a spherical hinge at the centre is necessarily the most efficient at supporting vertical loading of either a symmetrical or antisymmetrical nature. As structures of a low rise to span ratio generally behave in a nonlinear manner due to changes in geometry, it is suggested that part of the difference between the theoretical solution and the experimental results presented in the Paper may be attributable to these non-linear effects.

32. Was the method of analysis described in the Paper programmed and was it available for use by design engineers?

33. As an alternative to using the particular method of analysis outlined in the Paper, design engineers may prefer to use more general methods of analysis which are readily and cheaply available through many commercial outlets (e.g. Strudl, Nastran and Aska) and therefore it would be essential to know the relative economy and ease in using the Author's method.

\section{Dr Auld}

With regard to Dr Broughton's query as to the load supporting efficiency of a centre spherical hinge in a dome structure, this assumption is purely a device enabling the stress distribution to be determined by a simplified analytical approach which is sufficiently accurate for design purposes. Although close correlation between theoretical and experimental results was indicated for the model, in practice it would not

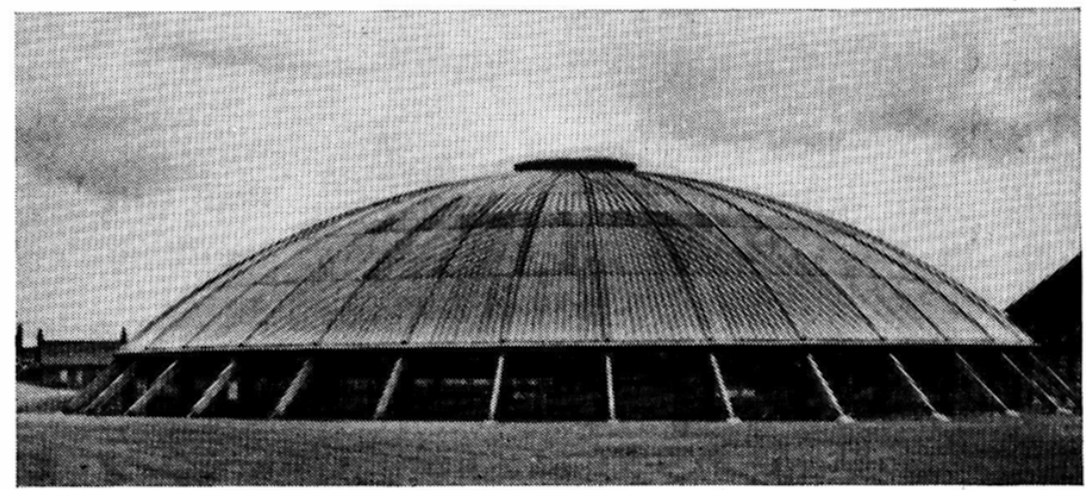

Fig. 19. The Lightfoot Sports Stadium, Newcastle-upon-Tyne-a circular arch-ribbed dome

Paper published: Proc. Instn Civ. Engrs, Part 2, 1973, 55, June, 391-410. 


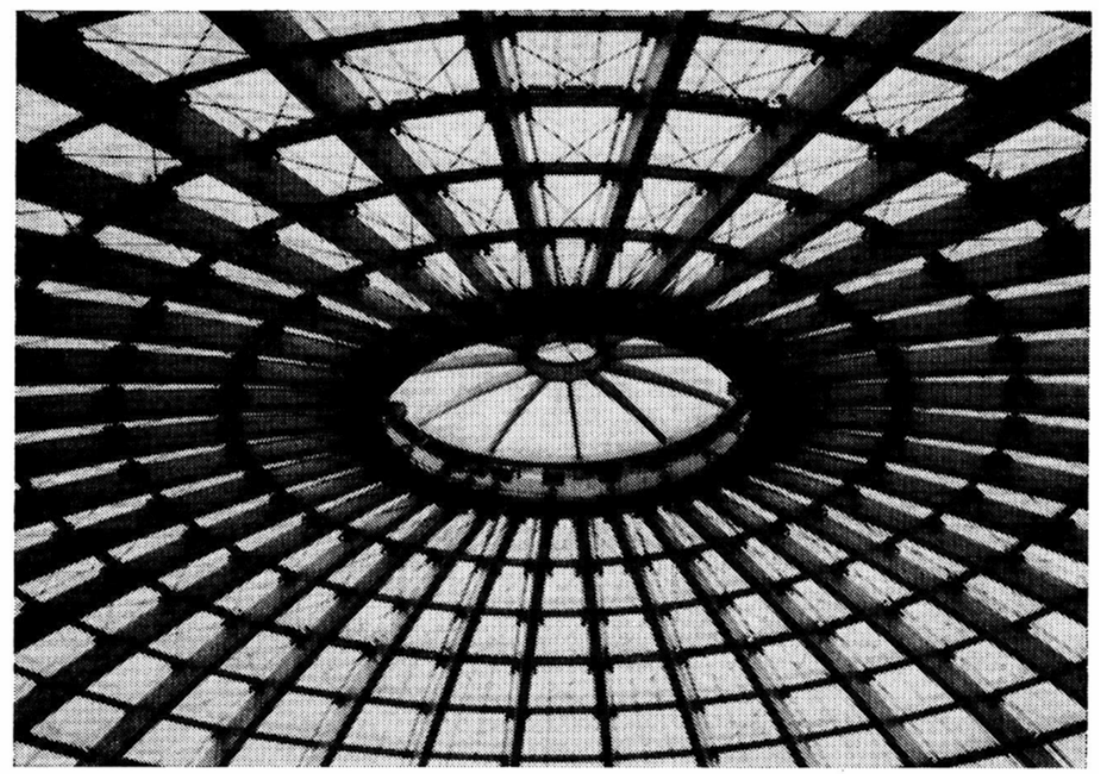

Fig. 20. The Lightfoot Stadium apex ring

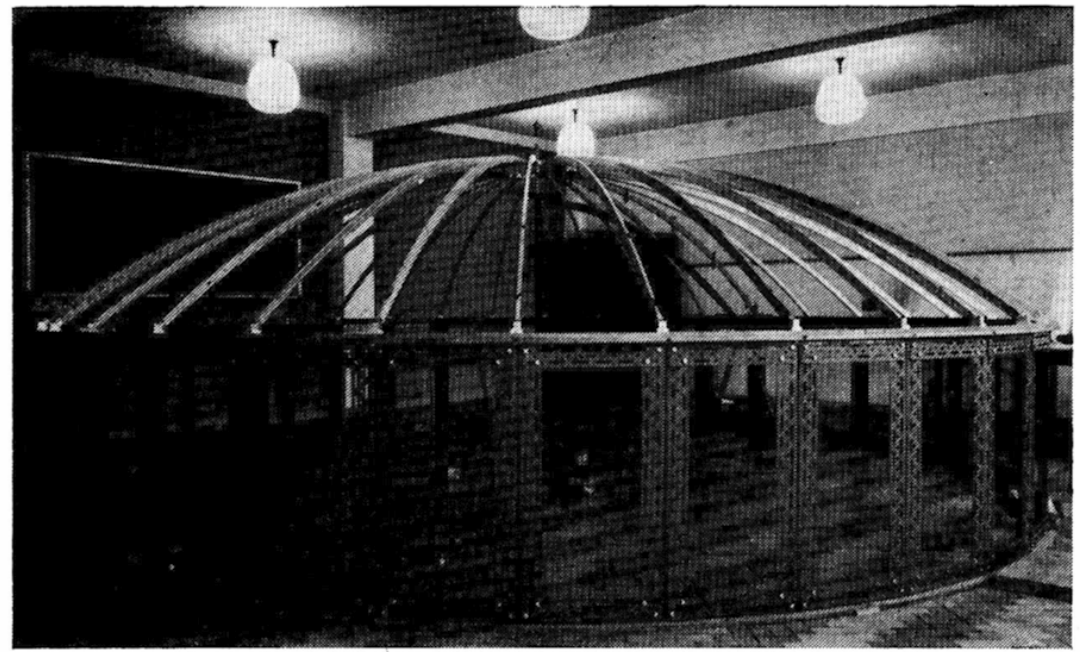

Fig. 21. Model arch-ribbed dome used in research at the University of Newcastleupon-Tyne 


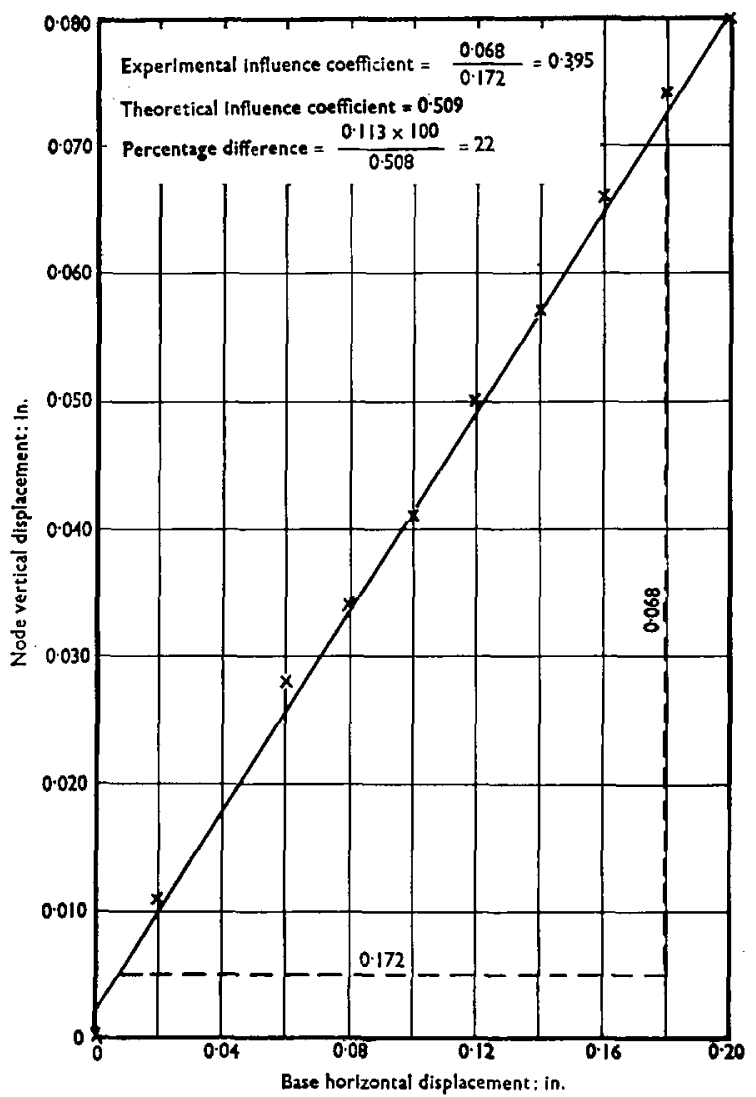

Fig. 22. Determination of influence coefficients; rib $0-4^{\prime}$, node 3 , Fig. 18

be possible to interconnect a large number of ribs together at a single apex point unless some degree of fixity were provided for stability. A typical circular archribbed dome is the Lightfoot Sports Stadium (Fig. 19) at Newcastle-upon-Tyne, which has a steel box section ring joining the radial ribs together at its apex (Fig. 20). Further research at the University of Newcastle-upon-Tyne, on another model based on the Lightfoot Stadium arrangement of radial ribs (Fig. 21), produced results for future publication indicating how accurate the method of analysis is when applied to arch-ribbed domes with apex rings.

35. I do not consider that part of the difference between the theoretical solution and the experimental results presented in the Paper could be attributable to nonlinearities produced by gross deformation. The deformations applied to the model dome during testing were very small compared with its overall dimensions and it can be seen from Fig. 22, as an example, that the behaviour was linear throughout. It is my opinion that the discrepancies in this case were more likely to be due to 
experimental errors associated with the operation of the displacement devices and measuring very small movements, in addition to the apex fixity effect.

36. However, I should like to point out that non-linear behaviour due to gross deformation could be an extremely important consideration in the design of some arch-ribbed domes. The engineer must choose, when designing domes with radial ribs continuous from base to crown, which method of analysis will give him the most accurate solution on the safe side in the time available. There are three options

(a) use the method described

(b) apply membrane theory

(c) use a more general method of analysis and matrix algebra techniques.

It is also possible to use a combination of these methods and the choice of method will depend on the configuration, size proportioning and joint details of the structural members. If the first method is employed, all the base reactions can be determined simply and quickly for any pattern of loading and bending moments, shear forces and axial forces then evaluated to give cross-section sizes for the ribs. This procedure results in a series of radial ribs which are strong enough to resist any loads independent of the additional strength provided by the secondary horizontal purlin rings, supporting the roof covering, and the diagonal bracing for lateral stability. My method is therefore an extension of the three-pinned arch plane frame analysis approach used in the design of the Lightfoot Stadium. For the horizontal purlin rings and diagonal bracing, pin-jointed connexions can be assumed at the radial ribs and the axial forces in these members determined as if the whole dome were a statically determinate pinjointed system. ${ }^{5,6}$ In the case of structures similar to the Lightfoot Stadium, with deep section radial ribs designed for bending strength, it would be very unlikely that gross deformation would occur.

37. The method of design described is simple and quick to apply but involves an overestimate of strength. Deep section, continuous radial ribs with small section members for the horizontal purlin rings and diagonal bracing will probably not produce the most economical structure with regard to material cost although they are ideal for easy erection. A more economical structure, as far as the material cost is concerned, could be produced by using a smaller sectional size of member uniformly throughout the system. Joint stiffness then has to be considered and my method would not be valid. Here, membrane theory related to shells of revolution would be more applicable as the forces are assumed to be axial with little or no bending occurring. When this design approach is employed non-linear characteristics have to be catered for in the form of general buckling, local buckling and member buckling. ${ }^{7}$ Shell conditions were studied in the case of the Lightfoot Stadium as an added check and the method is easily applied in the drawing office.

38. The third design approach, also mentioned by Dr Broughton, is the use of more general methods of analysis to give linear and non-linear solutions. They require the use of electronic computers and the commercial programs can be used where appropriate. I wrote and used a program to evaluate the reaction formulae quoted in the Paper but it was not developed for general use.

\section{References}

5. Benjamin B. S. The analysis of braced domes. Asia Publishing House, New York, 1963.

6. AMERICAN INSTITUTE OF TIMBER CONSTRUCTION. Timber construction manual, 1st ed. Wiley, New York, 1966, section 4, 63-67.

7. Buchert K. P. Buckling considerations in the design and construction of doubly curved space structures. In Space structures. Blackwell Scientific Publications, Oxford, 1967, 485-490. 